\title{
Monosomy 7 in donor cell-derived leukemia after bone marrow transplantation for severe aplastic anemia: Report of a new case and review of the literature
}

\author{
Luize Otero, Daiane Correa de Souza, Rita de Cássia Tavares, Bernadete Evangelho Gomes, \\ Telma França Padilha, Luiz Fernando Bouzas, Teresa de Souza Fernandez and Eliana Abdelhay \\ Centro de Transplante de Medula Óssea, Instituto Nacional de Câncer, \\ Rio de Janeiro, RJ, Brazil.
}

\begin{abstract}
Monosomy 7 arises as a recurrent chromosome aberration in donor cell leukemia after hematopoietic stem cell transplantation. We report a new case of donor cell leukemia with monosomy 7 following HLA-identical allogenic bone marrow transplantation for severe aplastic anemia (SAA). The male patient received a bone marrow graft from his sister, and monosomy 7 was detected only in the XX donor cells, 34 months after transplantation. The patient's bone marrow microenvironment may have played a role in the leukemic transformation of the donor hematopoietic cells.
\end{abstract}

Key words: monosomy 7, donor cell leukemia, bone marrow transplantation, severe aplastic anemia.

Received: December 12, 2012; Accepted: July 1, 2012.

Allogeneic bone marrow transplantation (BMT) is a successful therapy for patients with severe aplastic anemia (SAA). A rare complication after BMT for SAA is the development of acute leukemia (Klingemann et al., 1986). Cytogenetic or variable number tandem repeat (VNTR) analysis has shown that, in these rare cases, the leukemia originates in host cells. Donor cell leukemia (DCL) or donor cell myelodysplastic syndrome are complications that have been observed not only after hematopoetic transplantation with progenitor cells harvested from bone marrow and peripheral blood, but also after cord blood transplantation (Browne et al., 1991). Most of the DCL cases occurred in patients transplanted for acute leukemias. Only six cases of secondary leukemia in donor cells after BMT for SAA have been reported so far (Klingemann et al., 1986; Hughes et al., 1988; Browne et al., 1991; Lawler et al., 2002; Haltrich et al., 2003; Hashino et al., 2006). Hypotheses offered to explain the development of DCL include transfer of oncogenic material from host to donor cells, immunosuppression after BMT leading to inadequate immune surveillance, leukemic transformation of engrafted cells, and occult leukemia in the donor cells (Neglia et al., 1991). Here we report on a case of monosomy 7 in DCL following BMT for SAA in a Brazilian patient and discuss its possible causes.

Send correspondence to Luize Otero. Laboratório de Citogenética, Centro de Transplante de Medula Óssea, Instituto Nacional de Câncer, Praça da Cruz Vermelha 23, $6^{\circ}$ andar, Centro, 20230-130 Rio de Janeiro, RJ, Brazil. E-mail: luizeotero@ hotmail.com.
In January 2007, a 23-year-old man diagnosed with SAA was referred to our center for allogenic bone marrow transplantation from an HLA-identical sister. Prior to the procedure, the bone marrow aspirate revealed marked hypocellularity with a predominance of mature lymphocytes, and the bone marrow biopsy showed a $5 \%$ cellularity. Conventional cytogenetic analysis showed a normal $46, \mathrm{XY}$ karyotype in 24 metaphases. The conditioning regimen consisted of cyclophosphamide and ATG. Cyclosporin $\mathrm{A}$ and methotrexate were administered to prevent graft-versus-host disease (GVHD). The engraftment occurred on day $25\left(>500 / \mathrm{mm}^{3}\right.$ neutrophils for 3 consecutive days). After BMT, the patient developed multiple infections and persistent neutropenia. His bone marrow aspirate did not show any blasts or dysplasias. In September 2009, the patient's neutropenia worsened and he received granulocyte colony stimulating factor (G-CSF). Nevertheless, there was no clinical improvement and he developed anemia, neutropenia and thrombocytopenia. In December 2009, the treatment with G-CSF was discontinued. A bone marrow examination was performed and its result was consistent with acute myeloid leukemia (AML). The immunophenotype analysis showed $30 \%$ of blasts with myeloid and monocytic component features (AML M4/M5). Cytogenetic analysis showed $100 \%$ donor cells, and $7.6 \%$ of them presented monosomy 7 (Figure 1A). The karyotype of the donor bone marrow sample was normal in 40 metaphases analyzed after G-banding and FISH analysis detected no monosomy 7 in 200 cells studied (Figure 1B). In January 
A)

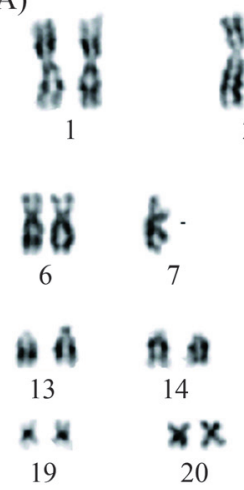

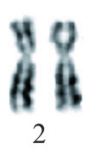

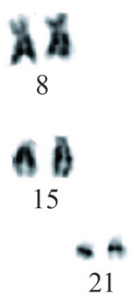

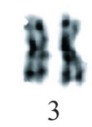
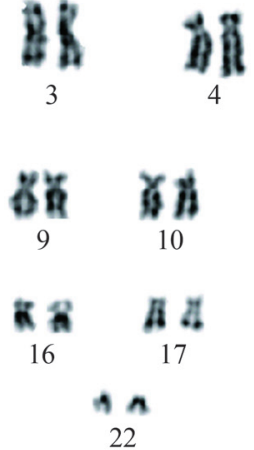

B)

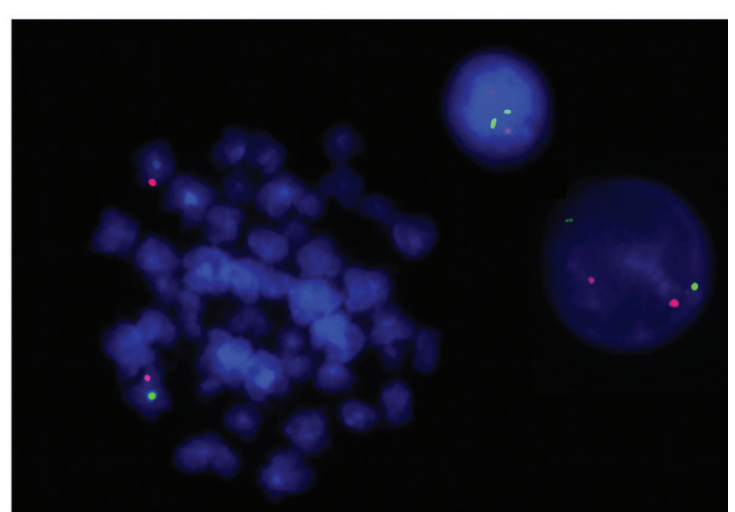

Figure 1 - Monosomy 7 after bone marrow transplantation. (A) Karyotype observed on day 1029 after BMT showing monosomy 7 in a female (donor) cell; (B) FISH images from donor bone marrow sample. The LSI CEP7/D75486 Dual Color Probe (Abbot Molecular, USA) hybridized to a normal metaphase and two interphase nuclei showing the two orange and two green signals on both chromosomes 7 .

2010, the patient underwent a second transplantation with G-CSF-mobilized peripheral blood cells from the same donor. The engraftment occurred on day 10. However, 15 days after the transplantation, the patient died due to refractory septic shock.

Literature reports on chromosome abnormalities resulting in hematological malignancies in donor cells after BMT are rare. Only a few cases of DCL have been reported after BMT for SAA. In the current case, we detected monosomy 7 in donor cells at day 1029 after BMT. Immunophenotype and morphological analysis confirmed the acute myeloid leukemia M4/M5 diagnosis at that time. Monosomy 7 in DCL after BMT for SAA was previously described by Lang et al. (2004). In their case, the donor cells were identified by microsatellite marker analysis, since patient and donor were both females. In our case, a male patient received a graft from his sister, and monosomy 7 was detected only in the XX donor cells. Monosomy 7 was also reported in one case of transient donor cell-derived myelodysplastic syndrome (Sevilla et al., 2006) and in one case of donor cell-derived acute monoblastic leukemia (Hamaki et al., 2008), after unrelated cord blood transplantation. In a recent study, Wang et al. (2011) described 10 cases of DCL, of which six had monosomy $7 / \operatorname{del}(7 q)$. Thus, monosomy 7 arises as a recurrent chromosome aberration in donor cell leukemia after hematopoietic stem cell transplantation. In general, monosomy 7 represents one of the most common chromosomal abnormalities in myelodysplastic syndromes, being present in approximately 50\% of therapy-related cases (Flactif et al., 1994). It probably arises at the level of myeloid progenitor cells and is usually associated with a very poor prognosis (Gerritsen et al., 1992). To investigate the possibility of occult leukemia cells in the donor, we performed conventional cytogenetic and FISH analysis, but no monosomy 7 was detected in the donor bone marrow sample. The mechanisms underlying the development of chromosomal abnormalities in donor cells are not fully understood so far. The microenvironment of our patient's bone marrow may have played a role in the development of monosomy 7 in the normal donor cells. This possibility was also suggested by Lang et al. (2004). We further believe that the impact of post-BMT immunosuppression, G-CSF utilization and local viral infection cannot be precisely assessed. A significantly increased incidence of MDS/AML was reported by the European Group for Blood and Marrow Transplantation in SAA patients receiving immunosuppressive therapy and G-CSF compared to those not receiving G-CSF (Socie et al., 2007). Some authors hypothesized that treatment with G-CSF might have played a role in the transformation of SAA into AML with monosomy 7 (Hashino et al., 1996). Another Japanese study demonstrated a substantial risk in children with SAA receiving G-CSF, and a high frequency of deletion of the long arm of chromosome 7 and monosomy 7 , was identified by FISH (Kojima et al., 2002). Notwithstanding, in a more recent study, Avalos et al. (2011) argued that the available clinical data do not provide evidence that G-CSF can transform donor normal hematopoietic stem cells in the absence of predisposing factors. The host microenvironment could play a role in the leukemic transformation. Our patient received G-CSF support 32 months after BMT, and monosomy 7 was detected two months after starting its use.

Our case highlights the fact that donor cell leukemia is an important entity in understanding the leukemogeneifc process.

\section{References}

Avalos BR, Lazaryan A and Copelan EA (2011) Can G-CSF cause leukemia in hematopoietic stem cell donors? Biol Blood Marrow Transplant 17:1739-1746.

Browne PV, Lawler M, Humphries P and McCann SR (1991) Donor-cell leukemia after bone marrow transplantation for severe aplastic anemia. N Engl J Med 325:710-713.

Flactif M, Lai JL, Preudhomme C and Fenaux P (1994) Fluorescence in situ hybridization improves the detection of mono- 
somy 7 in myelodysplastic syndromes. Leukemia 8:10121018 .

Gerritsen WR, Donohue J, Bauman J, Jhanwar SC, Kernan NA, Castro-Malaspina H, O'Reilly RJ and Bourhis JH (1992) Clonal analysis of myelodysplastic syndrome: Monosomy 7 is expressed in the myeloid lineage, but not in the lymphoid lineage as detected by fluorescent in situ hybridization. Blood 80:217-224.

Haltrich I, Müller J, Szabó J, Kovács G, Kóos R, Poros A, Dobos $\mathrm{M}$ and Fekete G (2003) Donor-cell myelodysplastic syndrome developing 13 years after marrow grafting for aplastic anemia. Cancer Genet Cytogenet 142:124-128.

Hamaki T, Kajiwara K, Kami M, Murashige N, Funaki M, Harima A, Kogure K, Yamada K, Kodo H and Kouzai Y (2008) Donor cell-derived acute monoblastic leukemia involving MLL gene translocation in an adult patient who received umbilical cord blood transplantation. Bone Marrow Transplant 41:91-92.

Hashino S, Fujisawa F, Kondo T, Imamura M, Sato K, Torimoto Y, Kohgo Y, Kimura K, Furukawa H, Todo S, et al. (2006) Donor-type myelodysplastic syndrome with $\mathrm{t}(2 ; 3)$ and monosomy 7 after allogeneic peripheral blood stem cell transplantation and liver transplantation in a patient with severe-type aplastic anemia. Int J Hematol 84:363-366.

Hashino S, Imamura M, Tanaka J, Kobayashi S, Musashi M, Kasai M and Asaka M (1996) Transformation of severe aplastic anemia into acute myeloblastic leukemia with monosomy 7. Ann Hematol 72:337-339.

Hughes RT, Milligan DW, Smith GM, Leyland MJ and Gordon-Smith EC (1988) A second bone marrow transplant for acute myeloid leukaemia after transplantation for aplastic anaemia. Br J Haematol 68:391.

Klingemann HG, Storb R, Sanders J, Deeg HJ, Appelbaum FR and Thomas ED (1986) Acute lymphoblastic leukaemia after bone marrow transplantation for aplastic anaemia. Br J Haematol 63:47-50.

Kojima S, Ohara A, Tsuchida M, Kudoh T, Hanada R, Okimoto Y, Kaneko T, Takano T, Ikuta K and Tsukimoto I (2002) Risk factors for evolution of acquired aplastic anemia into myelodysplastic syndrome and acute myeloid leukemia after immunosuppressive therapy in children. Blood 100:786-790.

Lang Z, Dinndorf P, Ladisch S, Bayever E and Reaman G (2004) Chromosomal transformation in donor cells following allogeneic bone marrow transplantation. Bone Marrow Transplant 33:1253-1256.

Lawler M, Locasciulli A, Longoni D, Schiro R and McCann SR (2002) Leukaemic transformation of donor cells in a patient receiving a second allogeneic bone marrow transplant for severe aplastic anaemia. Bone Marrow Transplant 29:453456.

Neglia JP, Meadows AT, Robison LL, Kim TH, Newton WA, Ruymann FB, Sather HN and Hammond GD (1991) Second neoplasms after acute lymphoblastic leukemia in childhood. N Engl J Med 325:1330-1336.

Sevilla J, Querol S, Molines A, González-Vicent M, Balas A, Carrió A, Estella J, Angel Díaz M and Madero L (2006) Transient donor cell-derived myelodysplastic syndrome with monosomy 7 after unrelated cord blood transplantation. Eur J Haematol 77:259-263.

Socie G, Mary JY, Schrezenmeier H, Marsh J, Bacigalupo A, Locasciulli A, Fuehrer M, Bekassy A, Tichelli A and Passweg J (2007) Granulocyte-stimulating factor and severe aplastic anemia: A survey by the European Group for Blood and Marrow Transplantation (EBMT). Blood 109:27942796.

Wang E, Hutchinson CB, Huang Q, Lu CM, Crow J, Wang FF, Sebastian S, Rehder C, Lagoo A, Horwitz M, et al. (2011) Donor cell-derived leukemias/myelodysplastic neoplasms in allogeneic hematopoietic stem cell transplant recipients: A clinicopathologic study of 10 cases and a comprehensive review of the literature. Am J Clin Pathol 135:525-540.

Associate Editor: Angela M. Vianna-Morgante

License information: This is an open-access article distributed under the terms of the Creative Commons Attribution License, which permits unrestricted use, distribution, and reproduction in any medium, provided the original work is properly cited. 